\title{
Resenha
}

\section{Psicoterapeuta: teoria e paciente ${ }^{1}$}

\author{
Psychotherapist: Theory and patient
}

\author{
Geraldina Porto WITTER $^{2}$ (in memorian)
}

No Brasil, a formação e a escolha da linha de psicoterapia a seguir é feita precocemente, no curso de graduação e sem ter acesso ou, o que é pior, já desenvolvendo falsas certezas e preconceitos a várias teorias. A vivência prática é muito superficial, restringe-se a duas ou três teorias. Infelizmente muitos acham que ao receber o diploma estão formados para todas as áreas e que conhecem todas as formas de psicoterapia, que estão aptos para o atendimento. Poucos fazem cursos de pósgraduação.

O livro de Derek Truscott foi publicado pela American Psychological Association como uma ajuda efetiva para a formação de psicoterapeutas eficientes e competentes na escolha da melhor teoria e procedimento a usar com cada paciente. De fato, espera-se que o terapeuta seja competente em várias teorias utilizáveis na psicoterapia. Hoje, estima-se que existem reconhecidas cerca de 250 teorias para sustentação de psicoterapias, sendo a maioria desconhecida no Brasil. A premissa vigente (vem da segunda metade do século $X X$ ) afirma que não há uma teoria "certa" de psicoterapia, ao contrário, o terapeuta precisa encontrar o enfoque que melhor pode atender a cada cliente e, se não for competente nele, encaminhá-lo para quem o seja, ou mesmo fazer unificação teórica quando viável. O próprio autor é considerado especialista e grande produtor de conhecimento nas teorias com que trabalha na prática e que apresenta no livro. Isso pede uma ampla revisão sobre com e em que nível se está pretendendo formar o psicoterapeuta no Brasil. A obra pede muito pensar sobre o que se está fazendo e sobre que psicoterapeutas se está formando para atuar no século que estamos vivendo.

O primeiro capítulo trata da adoção de uma teoria para cada paciente. Após um breve lembrar das terapias verbais já registradas nas antigas sociedades históricas como práticas verbais, retoma Freud que modernizou o conceito de psicoterapia e os desdobramentos que se seguiram. Considera as bases funcionais e úteis para fornecer uma estrutura de referência para o terapeuta formular hipóteses e para mudar o processo, bem como, avaliar o progresso em relação ao alvo da psicoterapia. Afirma que desde as últimas décadas o século passado o enfoque dominante entre os psicoterapeutas

$\boldsymbol{\nabla v} \nabla$

1 Truscott, D. (2010). Becoming and effective psyhchoterapist: Adapting a theory of psychotherapy that's right for you and your cliente. Washington, DC: APA. Available from: <http://psycnet.apa.org/books/12064>

2 Universidade Camilo Castelo Branco, Programas de Extensão Universitária. R. Carolina Fonseca, 584, Itaquera, 08230-230, São Paulo, SP, Brasil.E-mails:<gwitter@uol.com.br>; <unicastelo@unicastelo.br>. 
é o ecletismo enfoque teórico em que são selecionados procedimentos com apoio nas evidências, mas que é muito difícil, pois na prática, um referencial teórico pode ser de grande ajuda, servindo de guia no processo. Mas o problema que se coloca é fazer a escolha mais compatível para desenvolver a melhor prática para cada cliente. Esta escolha ocorre em um universo de teorias que se distribuem entre os eixos: de $x$ (objetividade-subjetividade) e de $y$ (analítico-vivencial). Descreve claramente o que e como proceder a escolha desenvolvendo-se como psicoterapeuta.

Nos capítulos seguintes o autor apresenta 10 das teorias mais frequentemente usadas. Todos seguem a mesma estrutura: apresentação da base racional, objetivos, processos de mudanças, tarefas psicoterapêuticas, relações terapeuta-paciente, bibliografia de estudos de caso, leituras recomendadas (base teórica) e revisões sobre elas. São clássicos de cada teoria, de modo que nem sempre a bibliografia é atual, para tanto é recomendável recorrer a livros e revistas especializadas mais recentes, preferencialmente dos últimos quatro ou cinco anos. Em todas tem uma foto ou desenho de seu criador, e relato de um caso, questões a pesquisar e proposta de uma estrutura psicoterápica bem realizada ou sucedida. Inclui os últimos desdobramentos do enfoque em novas propostas. Todos apresentam um resumo no final.

$\mathrm{Na}$ impossibilidade de apresentar todos os capítulos face ao número de páginas viável para resenha, optou-se por escolher apenas alguns exemplos, já que a estrutura e o tipo de informação encontrado em cada caso é da mesma natureza.

A primeira teoria apresentada (capítulo 2) é a Psicodinâmica lembrando que elas se reportam aos processos inconscientes inicialmente articulados por Freud, sem necessariamente incorporar a teoria freudiana como um todo. Psicanálise só se aplica aos que seguem a teoria freudiana como proposta pelo próprio Freud. Descreve sucintamente a base racional, os objetivos, os processos de mudanças, as tarefas de mudanças, as relações terapêuticas, a evolução e as variações da psicodinâmica. Entre as últimas, faz referência a Psicologia do Ego, Terapia 128
Psicoterapia Psicodinâmica Breve, Psicodinâmica Clínica, Terapia Psicodinâmica da Família.

Seguem os excelentes capítulos que apresentam as Psicoterapias: Behaviorista ou Comportamental, Existencial, Centrada na Pessoa, Gestáltica, Cognitiva, Sistêmica, Feminista e Construtivista.

Apresenta-se a seguir alguns exemplos mais recentes como complementação para dar ao leitor uma perspectiva mais abrangente do ótimo livro escrito por Truscott. Optou-se pelas mais recentes ou menos difundidas no Brasil.

Assim, o capítulo 7 trata da Terapia Cognitiva que começa a emergir nos anos sessenta do século XX como decorrência de behavioristas que buscavam desenvolver outras ferramentas para atuar em processos cognitivos (pensamento, memória, estratégias de processamento). Buscaram aprofundar o estudo e a ação por interações entre as pessoas e seu ambiente. Destacam-se na busca desta evolução Dember, Kuhn, Whorf, Bandura etc. Como os behavioristas não abandonaram o behaviorismo ao trabalharem neste enfoque isto facilitou a fusão das duas propostas que ocorre posteriormente. Também psicanalistas como Beck, Ellis e Dobson migraram para o modelo tentando fusões. Após a descrição básica da psicoterapia apresenta como evoluções ou variações: Psicoterapia Estrutural de Guidano e Lotti, Terapia Dialética Comportamental desenvolvida por Ryle e a Terapia Esquemática desenvolvida por Young. Dela emergiu a psicoterapia de maior uso e impacto na atualidade que a Psicoterapia Cognitiva-Behaviorista ou Comportamental- Cognitivista.

O capítulo seguinte trata da Psicoterapia Feminista que surgiu dos movimentos sociais e de direitos civis ocorridos nos anos 1960 nos Estados Unidos, em decorrência da contestação feminina de que o foco das psicoterapias não consideravam adequadamente as diferenças de gênero e tinham uma perspectiva masculina: Brown apresentou sua teoria e proposta de psicoterapia que embora muito criticada por uns, teve ampla aceitação entre outros e apoio em pesquisas. Apresenta sua base racional e o que a caracteriza. Como decorrência, a teoria serviu de apoio ao feminismo liberal, cultural, radical e socialista que culminou na Psicoterapia Feminista 
que evoluiu para incorporar aspectos da opressão social, de gênero, de raça, classe social e orientação sexual.

A Psicoterapia Construtivista (capítulo 10) é uma dos grupos de psicoterapias muito recentes. Embora de história breve ela já tem sido bastante contestada. O que a caracteriza é que vários psicoterapeutas passaram a se autodenominar construtivistas. Epistemologicamente tem sua origem da perspectiva racional de Vico e Kant e, do começo do século passado, com Vaihinger. "Tem por base a concepção de que a natureza da experiência humana é ativa, significando que se faz por si, e somente se pode construir um modelo de realidade" (p.141). Tem fundamentos originários de várias outras teorias, principalmente do pensamento de Kelly na psicoterapia baseada em papéis e na sua teoria de personalidade. Apresenta as características da proposta como nas teorias anteriores e como evolução a Terapia Narrativa desenvolvida pelos assistentes sociais White e Epson, a Terapia Orientada para Solução proposta por O'Hanlon e Shazer, a Colaborativa de Anderson e Goolishian e a Cognitiva Construtivista de Mahoney. O eixo é recorrer a questões especiais que viabilizem a reconstrução.

O último capítulo é uma orientação para que o psicoterapeuta adapte seu enfoque para ter êxito no bom atendimento ao seu cliente. O ponto principal em se adotar uma teoria é que ela deve servir de guia nas atividades que facilitarão o processo de mudança para se alcançar os objetivos do cliente. É só um aspecto do processo que depende da capacidade do terapeuta adaptar ao longo de sua carreira. É conhecido que a variação de resultados entre as teorias é muito menor de que a variação entre os terapeutas de uma mesma teoria. Vale dizer que o terapeuta faz mais diferença do que a teoria. Para ser eficiente ele deve estar atendo ao seu próprio desenvolvimento pessoal e profissional. Estar em contínua evolução implica em: (a) aprender uma teoria psicoterapêutica em que acredite; (b) aprender com a prática; (c) aprender e assimilar a base racional, tarefas e outros objetivos de outras teorias e (d) aprender a responder de acordo com as experiências e reações do cliente para estabelecer uma base racional para mudar, ou seja, precisa repetir o processo com várias teorias. Descreve cada item. É fundamental estar familiarizado com várias teorias para poder fazer opções mais adequadas e maximizar o próprio desenvolvimento. É um processo de mudanças contínuas para se atingir o pretendido.

Recebido em: 21/10/2011

Aprovado em: 4/11/2011 
